\title{
Tat-ATOX1 inhibits inflammatory responses via regulation of MAPK and NF-KB pathways
}

\author{
Dae Won Kim ${ }^{2, \#}$, Min Jea Shin ${ }^{1, \#}$, Yeon Joo Choi ${ }^{1, \#}$, Hyun Jung Kwon ${ }^{2}$, Sung Ho Lee ${ }^{3}$, Sunghou Lee ${ }^{4}$, Jinseu Park ${ }^{1}$, \\ Kyu Hyung Han ${ }^{1}$, Won Sik Eum, ${ }^{1, *}$ \& Soo Young Choi, ${ }^{1, *}$ \\ ${ }^{1}$ Department of Biomedical Science and Research Institute of Bioscience and Biotechnology, Hallym University, Chuncheon 24252, \\ ${ }^{2}$ Department of Biochemistry and Molecular Biology, Research Institute of Oral Sciences, College of Dentistry, Gangneung-Wonju National \\ University, Gangneung 25457, ${ }^{3}$ R\&D Center, Lumieye Genetics Co., Ltd., Seoul 06198, ${ }^{4}$ Department of Green Chemical Engineering, \\ Sangmyung University, Cheonan 31066, Korea
}

\begin{abstract}
Antioxidant 1 (ATOX1) protein has been reported to exhibit various protective functions, including antioxidant and chaperone. However, the effects of ATOX1 on the inflammatory response has not been fully elucidated. Thus, we prepared cell permeable Tat-ATOX1 and studied the effects on lipopolysaccharide (LPS)- and 12-O-tetradecanoyl phorbol-13acetate (TPA)-induced inflammation. Experimental results showed that transduced Tat-ATOX1 protein significantly suppressed LPS-induced intracellular reactive oxygen species (ROS). Also, Tat-ATOX1 protein markedly inhibited LPS- and TPA-induced inflammatory responses by decreasing cyclooxygenase-2 (COX-2) and inducible nitric oxide synthase (iNOS) and further inhibited phosphorylation of mitogen activated protein kinases (MAPKs; JNK, ERK and p38) and the nuclear factor-kappaB (NF-KB) signaling pathway. These results indicate that the Tat-ATOX1 protein has a pivotal role in inflammation via inhibition of inflammatory responses, suggesting Tat-ATOX1 protein may offer a therapeutic strategy for inflammation. [BMB Reports 2018; 51(12): 654-659]
\end{abstract}

\section{INTRODUCTION}

Inflammation is produced in response to infections caused by various stimuli, including microbial pathogens, chemicals or damaged cells. Chronic inflammation is highly associated with diseases, such as cancer, arthritis, and age-related diseases (1,

${ }^{*}$ Corresponding authors. Soo Young Choi, Tel: +82-33-248-2112; Fax: +82-33-248-3202; E-mail: sychoi@hallym.ac.kr; Won Sik Eum, Tel: +82-33-248-3221; Fax: +82-33-248-3202; E-mail: wseum@ hallym.ac.kr

${ }^{\text {"}}$ These authors contributed equally to this work.

https://doi.org/10.5483/BMBRep.2018.51.12.248

Received 26 October 2018, Revised 9 November 2018, Accepted 21 November 2018

Keywords: Inflammation, MAPK, NF-kB, Protein therapy, Tat-ATOX1
2). Macrophages are important immune cells, which ultimately trigger inflammatory responses via production of nitric oxide (NO), inducible NO synthase (iNOS), cyclooxygenase-2 (COX-2), tumor necrosis factor alpha (TNF- $\alpha$ ), interleukin (IL)-1 $\beta$ and IL-6 $(3,4)$. Lipopolysaccharide (LPS), one of the most powerful inflammatory stimulants, activates toll like receptors (TLR4) on macrophages, and eventually triggers the activation of nuclear factor-kappaB (NF- $\kappa B$ ) and mitogen activated protein kinase (MAPK) pathways $(5,6)$. NF-KB plays an important role in inflammation, apoptosis, cancer (7), and phosphorylation of MAPKs, such as extracellular signalregulated kinase (ERK), p38, and c-Jun N-terminal kinase (JNK) in LPS-induced macrophages involved in the activation of NF-KB $(1,8)$. Therefore, inhibition of NF- $\kappa B$ and MAPKs activation is an important therapeutic strategy for inflammatoryrelated diseases $(4,9)$.

Antioxidant 1 (ATOX1) is a small protein, highly expressed in the cerebral cortex and hippocampus. It plays a crucial role as a copper chaperone $(10,11)$. This protein has also been reported to protect cells against oxidative damage induced by hydrogen peroxide and streptozotocin (STZ) $(12,13)$. Changes in ATOX1 expression levels may contribute to the inflammatory response and antioxidant defense in cells (14, 15). In addition, inactivation of ATOX1 markedly increases cell sensitivity to stressors (16). In contrast, other studies have suggested that ATOX1 may act as a therapeutic protein in cancer and neuronal diseases (17-19). However, the effects of ATOX1 on the inflammatory response remains unclear.

Since protein transduction domains (PTDs) are known to be cell-permeable, PTDs are generally used to examine the effects of target proteins for treatment of various diseases. Previous studies have shown that PTD fusion proteins have the ability to transduce into cells and these proteins protected ROS-induced cell death (20-23). We also have demonstrated that Tat-ATOX1 transduced into cells protected against oxidative stress- or STZ-induced cell death $(13,24)$. In this study, we determined the effects of Tat-ATOX1 in LPS-induced Raw 264.7 cells and in a TPA-induced mouse model.

ISSN: 1976-670X (electronic edition)

Copyright (c) 2018 by the The Korean Society for Biochemistry and Molecular Biology

(ㄷ) This is an open-access article distributed under the terms of the Creative Commons Attribution Non-Commercial License (http://creativecommons.org/licenses/by-nc/4.0) which permits unrestricted non-commercial use, distribution, and reproduction in any medium, provided the original work is properly cited. 


\section{RESULTS AND DISCUSSION}

\section{Transduction of Tat-ATOX1 into Raw 264.7 cells}

Tat-ATOX1 and control ATOX1 proteins were prepared as described previously $(13,24)$. To identify the transduction of fusion protein, cells were pretreated with varying concentrations $(0.01-0.3 \mu \mathrm{M})$ of Tat-ATOX1 or with the same concentration over differing time periods (15-60 min). Next, the stability of Tat-ATOX 1 was investigated in the cells. Fig. 1A-1C shows transduction of protein, gradual degradation and persistence for up to $15 \mathrm{~h}$ in the cells. Further, we determined the intracellular distribution of transduced Tat-ATOX 1 by DAPI- and Alexa Fluor 488-staining. Fluorescence signals of Tat-ATOX1 were observed in the cytoplasm and nucleus in the cells (Fig. 1D). These results indicate that Tat-ATOX1 was transduced into Raw 264.7 cells.

Several studies have shown that PTD fused protein transduction can be used as a tool for the intracellular application of therapeutic proteins (20-23). In previous studies, we have shown that Tat fused proteins transduced into different cell lines $(13,24-27)$. Also, we investigated the effects of transduced Tat-ATOX1 against LPS-induced oxidative stress in Raw 264.7 cells. As shown in Fig. 1E, the production of intracellular ROS was drastically increased in LPS-exposed Raw 264.7 cells, whereas it was markedly reduced in cells exposed to transduced Tat-ATOX1. Our observations are consistent with other reports showing that ROS levels were markedly increased in ATOX $1^{-1-}$ mice, suggesting ATOX 1 is involved in ischemia-induced endothelial ROS production
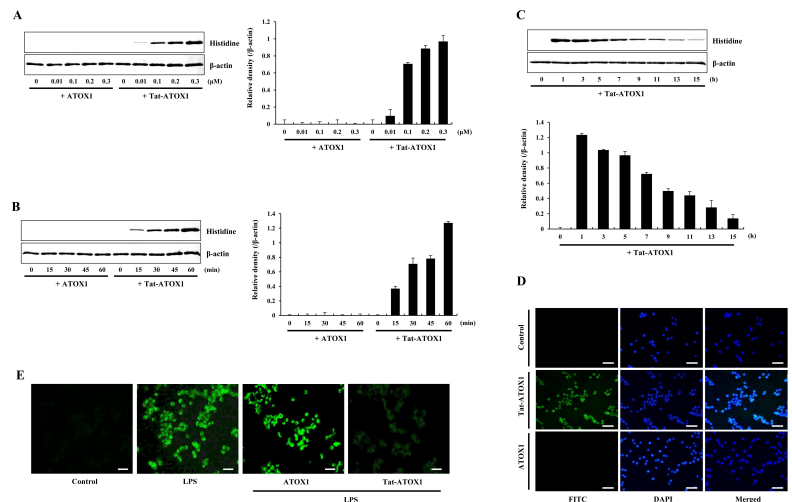

Fig. 1. Transduction of Tat-ATOX1 into Raw 264.7 cells. Tat-ATOX1 $(0.01-0.3 \mu \mathrm{M})$ was added to the culture media for $1 \mathrm{~h}$ (A) Tat-ATOX1 $(0.3 \mu \mathrm{M})$ was added to the culture media for $15-60 \mathrm{~min}(\mathrm{~B})$, cells were treated with $0.3 \mu \mathrm{M}$ of Tat-ATOX1 and incubated for $1-15 \mathrm{~h}$ and analyzed by Western blotting (C) and band intensities were measured by densitometry. The cells were treated with Tat-ATOX1 $(0.3 \mu \mathrm{M})$ for $1 \mathrm{~h}$ and distribution of transduced Tat-ATOX1 was confirmed by fluorescence microscopy (D). The effect of Tat-ATOX1 against LPS-induced ROS production in Raw 264.7 cells. Intracellular ROS levels were measured after staining with DCF-DA (E). Scale bar $=50 \mu \mathrm{m}$.
(14). Similarly, several studies have demonstrated that overexpression of ATOX1 inhibited neuronal cell death caused by hydrogen peroxide via reduction of cellular ROS levels. In addition, inactivation of ATOX1 has been shown to markedly increase cell sensitivity to various stressors $(16,17)$.

\section{Effects of Tat-ATOX1 on LPS-induced inflammatory responses in Raw 264.7 cells}

To investigate whether Tat-ATOX1 suppressed LPS-induced inflammatory responses in cells, pro-inflammatory mediator protein levels were examined. As shown in Fig. 2A, COX-2 and iNOS expressions were significantly increased in LPS-exposed cells. However, these expressions were markedly reduced when cells were pretreated with Tat-ATOX1, and control ATOX1 did not produce any effects.

Next, we examined the effect of Tat-ATOX1 against LPS-induced NF-KB and MAPK activation in Raw 264.7 cells. $\mathrm{NF}-\kappa \mathrm{B}$ is the major transcription factor of the inflammatory response to LPS. LPS-induced MAPK signaling pathways have been implicated in the inflammatory response through NF- $\mathrm{KB}$ activation (28-30). As shown in Fig. $2 \mathrm{~B}$ and 2C, phosphorylated NF-KB and MAPKs (p38, JNK, and ERK) levels were markedly increased in LPS-exposed cells. However, Tat-ATOX1 significantly reduced NF-KB and MAPKs activation whereas
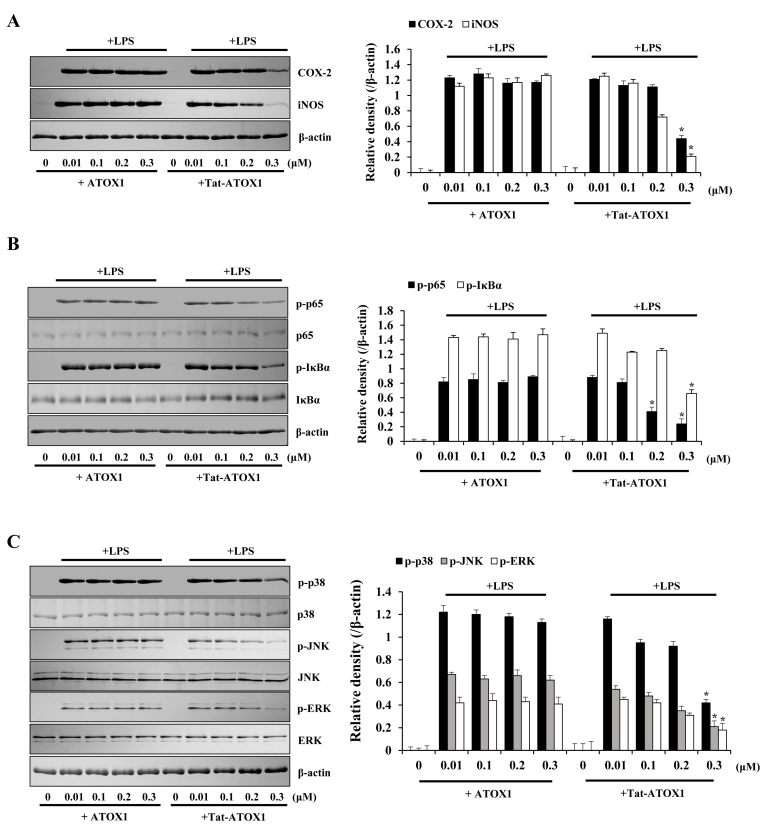

Fig. 2. Effects of Tat-ATOX1 on LPS-induced inflammatory responses in Raw 264.7 cells. The cells were pretreated with Tat-ATOX1 $(0.3 \mu \mathrm{M})$ for $1 \mathrm{~h}$, then treated with LPS $(1 \mu \mathrm{g} / \mathrm{ml})$. Expression levels of COX-2 and iNOS protein (A), NF- $\kappa B(B)$ and MAPK (C) activation were determined by Western blotting. The band intensity was measured by densitometry. ${ }^{*} P<0.01$, compared to LPS-treated cells. 
this activation was not affected in control ATOX1-treatment cells. These results indicate that transduced Tat-ATOX1 inhibits LPS-induced inflammatory responses by inhibition of NF-KB and MAPK activation in Raw 264.7 cells. In agreement with our results, many studies have shown that the phosphorylation levels of NF-KB and MAPKs were markedly increased in LPS-exposed cells, whereas treatment with various antiinflammatory substances markedly inhibited inflammatory responses through inhibition of COX-2 and iNOS expression, and NF-KB and MAPKs activation (31-33).

\section{Effects of Tat-ATOX1 on skin inflammation}

Other studies have used TPA, a powerful promoter of skin inflammation, to examine skin inflammation in animal models $(34,35)$. We examined whether Tat-ATOX1 protein showed anti-inflammatory effects against TPA-induced ear edema in a mouse model. Ear thickness and weights were drastically increased in the TPA-treated groups, while topically applied Tat-ATOX1 significantly reduced TPA-induced increases in ear thickness and weights, compared to the TPA-treated groups (Fig. 3). Also, we determined whether Tat-ATOX1 inhibits

A

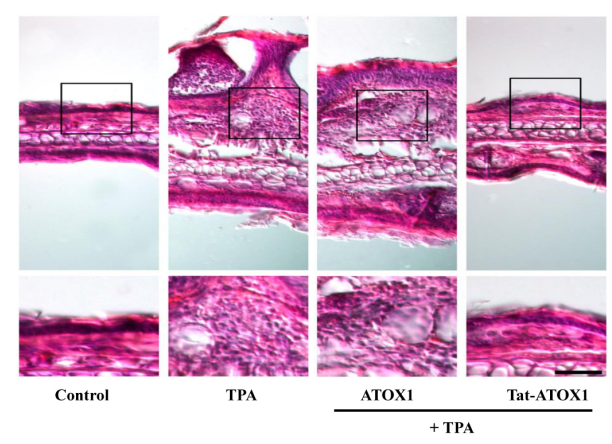

B
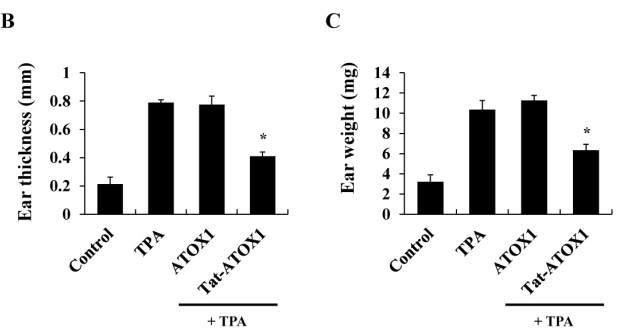

Fig. 3. Effects of Tat-ATOX1 on ear edema in a TPA-induced mice model. Ears of mice were exposed to TPA (1 $\mu \mathrm{g} / \mathrm{ear})$. Tat-ATOX1 $(10 \mu \mathrm{g})$ was topically applied to mice ears $1 \mathrm{~h}$ after TPA treatment for 3 days. The inhibition of TPA-induced ear edema was analyzed by hematoxylin and eosin immunostaining (A), changes in ear thickness (B), and ear weights (C). Scale bar $=50 \mu \mathrm{m}$ (top panel) and $25 \mu \mathrm{m}$ (bottom panel). ${ }^{*} \mathrm{P}<0.01$, compared to TPA-treated mice.
COX-2 and iNOS expression, as well as NF-KB and MAPKs activation in an animal model. Topically applied Tat-ATOX1 markedly inhibited COX-2 and iNOS expression (Fig. 4A). Furthermore, topically applied Tat-ATOX1 inhibited the activation of NF-KB and MAPKs. However, control ATOX1 did not show the same effects (Fig. $4 \mathrm{~B}$ and $4 \mathrm{C}$ ). These results demonstrated the protective effect of Tat-ATOX1 on TPAinduced skin inflammation. Several studies have reported that inhibitory substances of NF-KB, MAPKs, and cytokines protected against the TPA-induced inflammation and that they can be used as therapeutic agents for skin inflammatory diseases (36, 37). Kamiya et al (2018) demonstrated that overexpression of ATOX1 induced the expression of SOD3 and enhanced TPA-elicited SOD3 induction in TPA-treated THP-1 cells (38). Ha et al (2006) demonstrated that SOD3, an anti-oxidant protein, plays an important role in the inhibition of TPA-induced inflammation and epidermal hyperplasia by
A

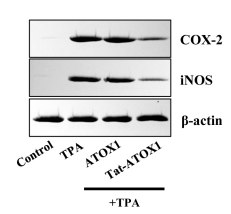

B

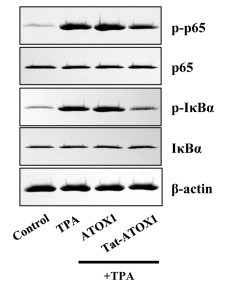

C

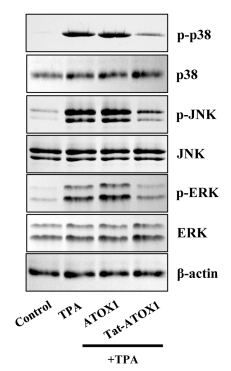

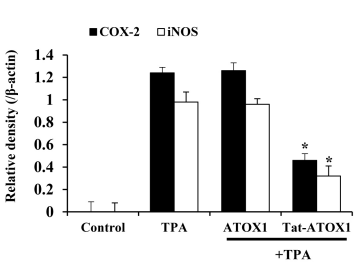
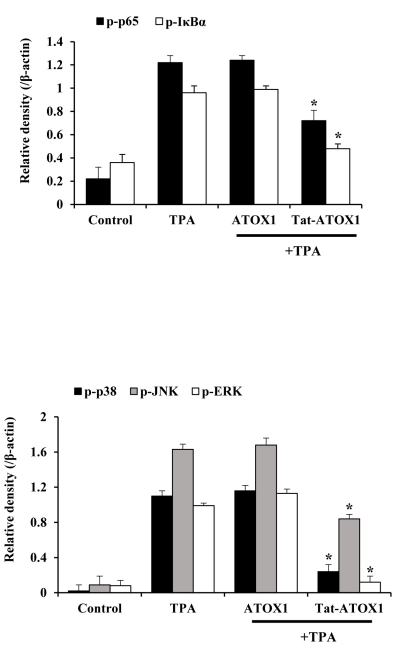

Fig. 4. Effect of Tat-ATOX1 against TPA-induced pro-inflammatory mediator proteins (COX-2 and iNOS), NF- $\mathrm{KB}$ and MAPK activation in mice ears. Tat-ATOX1 $(10 \mu \mathrm{g})$ was topically applied to mice ears $1 \mathrm{~h}$ after daily treatment with TPA $(1 \mu \mathrm{g} /$ ear) for 3 days. After ear biopsies were prepared, the expression levels of pro-inflammatory mediator proteins (A), NF- $\mathrm{KB}(\mathrm{B})$ and MAPK (C) activation were analyzed by Western blotting. Band intensities were measured by densitometry. ${ }^{*} \mathrm{P}<0.01$, compared to TPAtreated mice. 
regulation of pro-inflammatory cytokines in the skin of SOD3 transgenic mice (39). Also, other studies have shown that TPA-induced cell proliferation and DNA damage were inhibited, and tumor formation was reduced in a DMBATTPA-induced skin carcinogenesis model using overexpressed EC-SOD transgenic mice, suggesting EC-SOD plays a protective role in DMBATTPA-induced skin carcinogenesis (40). However, further research is required to clarify the molecular mechanisms underlying function of ATOX1 in macrophages and skin inflammation.

In summary, we have shown that transduced Tat-ATOX1 markedly suppressed inflammatory responses in LPS-exposed Raw 264.7 cells and in a TPA-induced animal model by inhibition of pro-inflammatory mediator proteins, as well as activated NF-KB and MAPK, suggesting that Tat-ATOX1 may contribute to the development of therapeutic proteins for the treatment of skin inflammation.

\section{MATERIALS AND METHODS}

\section{Materials and cell culture}

Tat-ATOX1 and control ATOX1 protein were prepared in our laboratory as described previously $(13,24)$. Histidine, COX-2, and iNOS antibodies were obtained from Santa Cruz Biotechnology (Santa Cruz, CA, USA). LPS and TPA were purchased from Sigma-Aldrich (St. Louis, MO, USA). Other antibodies were purchased from Cell Signaling Technology (Beverly, MA, USA). Male ICR mice (4-6 weeks old) were obtained from the Experimental Animal Center at Hallym University. All other agents were of the highest grade available, unless otherwise stated.

Raw 264.7 murine macrophage cells were cultured in Dulbecco's modified Eagle's medium (DMEM) containing 20 $\mathrm{mM} \mathrm{HEPES} / \mathrm{NaOH}$ (pH 7.4), $5 \mathrm{mM} \mathrm{NaHCO}, 10 \%$ fetal bovine serum (FBS), and antibiotics $(100 \mu \mathrm{g} / \mathrm{ml}$ streptomycin, 100 $\mathrm{U} / \mathrm{ml}$ penicillin) at $37^{\circ} \mathrm{C}$ under humidified conditions of $95 \%$ air and $5 \% \mathrm{CO}_{2}$.

\section{Purification and transduction of Tat-ATOX1 protein}

Tat-ATOX1 protein was purified as described previously (13, 24). Purified Tat-ATOX1 and control ATOX1 were treated with Detoxi-Gel $^{\mathrm{TM}}$ (Pierce, Rockford, IL, USA), according to manufacturer's instruction to remove endotoxin of proteins. We measured the amount of endotoxin in the proteins $(<0.03$ $\mathrm{EU} / \mathrm{ml}$ ) using a Limulus amoebocyte lysate assay (BioWhitaker, Walkersville, MD, USA). The protein concentration was determined using the Bradford assay (41).

To assess the transduction of Tat-ATOX1, Raw 264.7 cells were treated with varying concentrations of Tat-ATOX1 or control ATOX1 (0.01-0.3 $\mu \mathrm{M})$ for $1 \mathrm{~h}$. Some cells were treated with Tat-ATOX1 or control ATOX1 at one concentration $(0.3$ $\mu \mathrm{M})$ for various times $(15-60 \mathrm{~min})$. Cells were treated with trypsin-EDTA, washed with phosphate-buffered saline (PBS) and harvested to perform Western blot analysis.

\section{Western blot analysis}

Western blot analysis was performed, as described previously $(24,42)$. Equal amounts of sample proteins were separated with 15\% SDS-PAGE and transferred to a nitrocellulose membrane. The membrane was blocked with $5 \%$ nonfat dry milk in TBST buffer $(25 \mathrm{mM}$ Tris- $\mathrm{HCl}, 140 \mathrm{mM} \mathrm{NaCl}, 0.1 \%$ Tween 20, pH 7.5) for $1 \mathrm{~h}$. The membranes were immunoblotted with the indicated primary and HRP-conjugated secondary antibodies, as recommended by the manufacturer. The protein bands were detected using enhanced chemiluminescent reagents (Amersham, Franklin Lakes, NJ, USA).

\section{Fluorescence microscopy analysis}

Fluorescence microscopy analysis was performed as described previously $(24,35)$. Raw 264.7 cells were grown on coverslips and treated with $0.3 \mu \mathrm{M}$ of Tat-ATOX 1 protein for $1 \mathrm{~h}$ at $37^{\circ} \mathrm{C}$. Then, the cells were washed twice with PBS and fixed with $4 \%$ paraformaldehyde for $5 \mathrm{~min}$ at room temperature. The cells were permeabilized and blocked for 40 min with 3\% bovine serum albumin, $0.1 \%$ Triton X-100 in PBS (PBS-BT) and washed with PBS-BT. The primary antibody (Histidine) was diluted 1:2000, and incubated for $1 \mathrm{~h}$ at room temperature. The secondary antibody (Alexa Fluor 488, Invitrogen) was diluted 1:15000, and incubated for $1 \mathrm{~h}$ at room temperature in the dark. Nuclei were stained for 2 min with 1 $\mu \mathrm{g} / \mathrm{ml}$ DAPI (Roche). The distributions of fluorescence were analyzed using a fluorescence microscope (Nikon Eclipse 80i; Nikon, Tokyo, Japan).

\section{Measurement of ROS levels}

Raw 264.7 cells were incubated in the absence or presence of Tat-ATOX1 $(0.3 \mu \mathrm{M})$ for $1 \mathrm{~h}$, and then treated with LPS (1 $\mu \mathrm{g} / \mathrm{ml}$ ) for $30 \mathrm{~min}$. Cells were then washed twice with PBS and incubated with DCF-DA $(20 \mu \mathrm{M})$ for $15 \mathrm{~min} .2^{\prime}, 7^{\prime}$-dichlorofluorescein diacetate (DCF-DA) staining was performed according to the manufacturer's instructions $(24,35)$. Images were taken using a fluorescence microscope (Nikon eclipse $80 \mathrm{i}$, Japan).

\section{TPA-induced mouse ear edema model}

Male ICR mice were housed at constant temperature $\left(23^{\circ} \mathrm{C}\right)$ and relative humidity $(60 \%)$ with a fixed $12 \mathrm{~h}$ light: $12 \mathrm{~h}$ dark cycle and free access to food and water. All experimental procedures involving animals and their care conformed to the Guide for the Care and Use of Laboratory Animals of the National Veterinary Research and Quarantine Service of Korea and were approved by the Hallym Medical Center Institutional Animal Care and Use Committee.

TPA-induced mouse ear edema models were prepared as described previously (35). To examine the effects of Tat-ATOX1 against TPA-induced ear edema, the mice were divided into four groups ( $\mathrm{n}=5$ per group). The experimental groups were as follows: 1) normal control mice, 2) TPA-induced ear edema mice, 3) TPA + control ATOX1 
treated mice, and 4) TPA + Tat-ATOX1 treated mice. TPA (1.0 $\mu \mathrm{g})$ dissolved in $20 \mu \mathrm{l}$ of acetone was applied to the inner and outer surfaces of the mice ears every day for 3 days. Tat-ATOX1 (10 $\mu \mathrm{g})$ protein was topically applied to the mice ears every day for $1 \mathrm{~h}$ after TPA treatment. After the final treatment with TPA and Tat-ATOX1, mice were sacrificed, and ear biopsies were obtained. Ear thicknesses were measured using a digital thickness gauge (Mitutoyo Corporation, Toyko, Japan). Ear weights were measured after $5 \mathrm{~mm}$ diameter ear biopsies were obtained from each group using a punch (Kai Industries, Gifu, Japan). For histological analyses, ear biopsies were fixed in $4 \%$ paraformaldehyde, embedded in paraffin, sectioned at a thickness of $5 \mu \mathrm{m}$, then stained with hematoxylin and eosin.

\section{Statistical analysis}

Data represent the mean of three experiments \pm SD. Differences between groups were analyzed by one-way analysis of variance followed by a Bonferroni's post-hoc test using GraphPad Prism software (version 5.01; GraphPad Software Inc., San Diego, CA, USA). ${ }^{* P}<0.01$ was considered to indicate a statistically significant difference.

\section{ACKNOWLEDGEMENTS}

This research was supported by the Bio \& Medical Technology Development Program of the National Research Foundation (NRF) funded by the Korean government (MSIT) (2018M 3A9C8023568).

\section{CONFLICTS OF INTEREST}

The authors have no conflicting interests.

\section{REFERENCES}

1. Martinon F, Mayor A and Tschopp J (2009) The inflammasomes: guardians of the body. Annu Rev Immunol 27, 229-265

2. Medzhitov R (2008) Origin and physiological roles of inflammation. Nature 454, 428-435

3. Hiraiwa K and van Eeden SF (2013) Contribution of lung macrophages to the inflammatory responses induced by exposure to air pollutants. Mediators Inflamm 2013, 619523

4. Fujiwara $N$ and Kobayashi K (2005) Macrophages in inflammation. Curr Drug Targets Inflamm Allergy 4, 281-286

5. Laskin DL, Sunil VR, Gardner CR and Laskin JD (2011) Macrophages and tissue injury: agents of defense or destruction? Annu Rev Pharmacol Toxicol 51, 267-288

6. Haque MA, Jantan I and Harikrishnan H (2018). Zerumbone suppresses the activation of inflammatory mediators in LPS-stimulated U937 macrophages through MyD88dependent NF-кB/MAPK/PI3K-Akt signaling pathways. Int Immunopharmacol 55, 312-322
7. Aggarwal BB (2004) Nuclear factor-kappaB: the enemy within. Cancer Cell 6, 203-208

8. Yang Y, Kim SC, Yu T et al (2014) Functional roles of p38 mitogen activated protein kinase in macrophage-mediated inflammatory responses. Mediators Inflamm 2014, 352371

9. Hwang PA, Chien SY, Chan YL et al (2011) Inhibition of lipopolysaccharide (LPS)-induced inflammatory responses by Sargassum hemiphyllum sulfated polysaccharide extract in RAW 264.7 macrophage cells. J Agric Food Chem 59, 2062-2068

10. Hung IH, Casareno RL, Labesse G, Mathews FS and Gitlin JD (1998) HAH1 is a copper-binding protein with distinct amino acid residues mediating copper homeostasis and antioxidant defense. J Biol Chem 273, 1749-1754

11. Montes S, Rivera-Mancia S, Diaz-Ruiz A, Tristan-Lopez L and Rios C (2014) Copper and copper proteins in Parkinson's disease. Oxid Med Cell Longev 147251, 2014

12. Kelner GS, Lee M, Clark ME et al (2000) The copper transport protein Atox1 promotes neuronal survival. J Biol Chem 275, 580-584

13. Ahn EH, Kim DW, Shin MJ et al (2016) Tat-ATOX1 inhibits streptozotocin-induced cell death in pancreatic RINm5F cells and attenuates diabetes in a mouse model. Int J Mol Med 38, 217-224

14. Chen GF, Sudhahar V, Youn SW et al (2015) Copper transport protein antioxidant-1 promotes inflammatory neovascularization via chaperone and transcription factor function. Sci Rep 5, 14780

15. Hasselbalch HC, Thomassen M, Riley $\mathrm{CH}$ et al (2014) Whole blood transcriptional profiling reveals deregulation of oxidative and antioxidative defence genes in myelofibrosis and related neoplasms. Potential implications of downregulation of Nrf2 for genomic instability and disease progression. PLoS One 9, e112786

16. Hatori Y, Clasen S, Hasan NM, Barry AN and Lutsenko S (2012) Functional partnership of the copper export machinery and glutathione balance in human cells. J Biol Chem 287, 26678-26687

17. Kelner GS, Lee M, Clark ME et al (2000) The copper transport protein Atox1 promotes neuronal survival. J Biol Chem 275, 580-584

18. Ozumi K, Sudhahar V, Kim HW et al (2012) Role of copper transport protein antioxidant 1 in angiotensin II-induced hypertension: a key regulator of extracellular superoxide dismutase. Hypertension 60, 476-486

19. Dolgova NV, Nokhrin $\mathrm{S}, \mathrm{Yu} \mathrm{CH}$, George $\mathrm{GN}$ and Dmitriev OY (2013) Copper chaperone Atox1 interacts with the metal-binding domain of Wilson's disease protein in cisplatin detoxification. Biochem J 454, 147-156

20. Wadia JS and Dowdy SF (2002) Protein transduction technology. Curr Opin Biotechnol 13, 52-56

21. van den Berg A and Dowdy SF (2011) Protein transduction domain delivery of therapeutic macromolecules. Curr Opin Biotechnol 22, 888-893

22. Kubo E, Fatma N, Akagi Y, Beier DR, Singh SP and Singh DP (2008) TAT-mediated PRDX6 protein transduction protects against eye lens epithelial cell death and delays lens opacity. Am J Physiol Cell Physiol 294, C842-C855 
23. Embury J, Klein D, Pileggi A et al (2001) Proteins linked to a protein transduction domain efficiently transduce pancreatic islets. Diabetes 50, 1706-1713

24. Kim SM, Hwang IK, Yoo KY et al (2015) Tat-antioxidant 1 protects against stress-induced hippocampal HT-22 cells death and attenuate ischemic insult in animal model. J Cell Mol Med 19, 1333-1345

25. Yeo HJ, Yeo EJ, Shin MJ et al (2018) Protective effects of Tat-DJ-1 protein against streptozotocin-induced diabetes in a mice model. BMB Rep 51, 362-367

26. Jo HS, Eum WS, Park EY et al (2017) Effects of PEP-1-FK506BP on cyst formation in polycystic kidney disease. BMB Rep 50, 460-465

27. Jo HS, Kim DW, Shin MJ et al (2017) Tat-HSP27 inhibits oxidative stress-induced hippocampal neuronal cell death by regulation of the mitochondrial pathway. Mol Brain 10,1

28. Shi Q, Cao J, Fang L et al (2014) Geniposde suppresses LPS-induced nitric oxide, PGE2 and inflammatory cytokine by downregulating NF-kappaB, MAPK and AP-1 signaling pathways in macrophages. Int Immunopharmacol 20, 298-306

29. Lee HJ, Shin JS, Lee WS et al (2016) Chikusetsusaponin IVa methyl ester isolated from the roots of achyranthes japonica suppresses LPS-induced iNOS, TNF-alpha, IL-6, and IL-1beta expression by NF-kappaB and AP-1 inactivation. Biol Pharm Bull 39, 657-664

30. Yodkeeree S, Ooppachai C, Pompimon W and Limtrakul P (2018) O-methybulbocapnine and dicentrine suppress LPS-induced inflammatory responses by blocking NF-KB and AP-1 inactivation through inhibition MAPKs and Akt signaling in RAW264.7 macrophages. Biol Pharm Bull 41, 1219-1227

31. Qiang Z, Ko CH, Siu WS et al (2018) Inhibitory effect of different Dendrobium species on LPS-induced inflammation in macrophages via suppression of MAPK pathways. Chin J Nat Med 16, 481-489

32. Harikrishnan $\mathrm{H}$, Jantan I, Haque MA and Kumolosasi $\mathrm{E}$ (2018) Anti-inflammatory effect of phyllanthus amarus Schum. \& Thonn. Through inhibition of NF-кB, MAPK, and PI3K-Akt signaling pathways in LPS-induced human macrophages. BMC Complement Altern Med 18, 224
33. Islam SU, Lee JH, Shehzad A, Ahn EM, Lee YM and Lee YS (2018) Decursinol angelate inhibits LPS-induced macrophages polarization through modulation of the NF-KB and MAPK signaling pathways. Molecules 23, 1880

34. Stanley $\mathrm{PL}$, Steiner $\mathrm{S}$, Havens $\mathrm{M}$ and Tramposch $\mathrm{KM}$ (1991) Mouse skin inflammation induced by multiple topical applications of 12-O-tetradecanoyl phorbol-13acetate. Skin Pharmacol 4, 262-271

35. Kim MJ, Jeong HJ, Kim DW et al (2014) PEP-1-PON1 protein regulates inflammatory response in raw 264.7 macrophages and ameliorates inflammation in a TPAinduced animal model. PLoS One 9, e86034

36. Hsu CH, Ho YS, Lai CS et al (2013) Hexahydro- $\beta$-acids potently inhibit 12-O-tetradecanoylphorbol 13-acetateinduced skin inflammation and tumor promotion in mice. J Agric Food Chem 61, 11541-11549

37. Kulkarni NM, Muley MM, Jaji MS et al (2015) Topical atorvastatin ameliorates 12-O-tetradecanoylphorbol-13acetate induced skin inflammation by reducing cutaneous cytokine levels and NF-KB activation. Arch Pharm Res 28, 1238-1247

38. Kamiya T, Takeuchi K, Fukudome S, Hara H and Adachi T (2018) Copper chaperone antioxidant-1, Atox-1, is involved in the induction of SOD3 in THP-1 cells. Biometals 31, 61-68

39. Ha HY, Kim Y, Ryoo ZY and Kim TY (2006) Inhibition of the TPA-induced cutaneous inflammation and hyperplasia by EC-SOD. Biochem Biophys Res Commun 348, 450-458

40. Kim SH, Kim MO, Gao P et al (2005) Overexpression of extracellular superoxide dismutase (EC-SOD) in mouse skin plays a protective role in DMBA/TPA-induced tumor formation. Oncol Res 15, 333-341

41. Bradford M (1976) A rapid and sensitive method for the quantitation of microgram quantities utilizing the principle of protein-dye binding. Anal Biochem 72, 248-254

42. Yang SJ, Kim J, Lee SE, Ahn JY, Choi SY and Cho SW (2017) Anti-inflammatory and anti-oxidative effects of 3-(naphthalen-2-yl(propoxy)methyl)azetidine hydro chloride on $\beta$-amyloid-induced microglial activation. BMB Rep 50, 634-639 